\title{
The effects of submaximal exercise on a treadmill on the recovery of the stiffness index and reflection index in men with untreated hypertension
}

\author{
Kamila Miętkiewska-Szwacka \\ Department of Internal Medicine, Poznan \\ University of Medical Sciences, Poland \\ (iD) https://orcid.org/0000-0002-5977-4620 \\ Corresponding author: kamila.mietkiewska@gmail.com

\section{Magdalena Kujawska-Łuczak} \\ Department of Internal Medicine, Metabolic Disorders, and \\ Hypertension, Poznan University of Medical Sciences, Poland \\ (D) https://orcid.org/0000-0003-2008-6633
}

\section{Tomasz Piorunek}

Department of Pulmonology, Allergology, and Respiratory Oncology, Poznan University of Medical Sciences, Poland

(iD) https://orcid.org/0000-0002-2257-4967

\section{Szczepan Cofta}

Department of Pulmonology, Allergology, and Respiratory Oncology, Poznan University of Medical Sciences, Poland

(iD) https://orcid.org/0000-0002-8849-5487

\section{Karolina Hoffmann}

Department of Internal Medicine, Metabolic Disorders, and Hypertension, Poznan University of Medical Sciences, Poland (iD) https://orcid.org/0000-0001-6148-4094

\section{Katarzyna Grabańska-Martyńska}

Department of Internal Medicine, Poznan University of Medical Sciences, Poland

(iD) https://orcid.org/0000-0003-2219-1883

\section{Magdalena Roszak}

Department of Computer Science and Statistics, Poznan University of Medical Sciences, Poland

(iD) https://orcid.org/0000-0001-6495-6771

\author{
Ewa Wysocka \\ Department of Laboratory Diagnostics, Poznan \\ University of Medical Sciences, Poland \\ (iD) https://orcid.org/0000-0002-4101-7656 \\ Maciej Cymerys \\ Department of Internal Medicine, Poznan \\ University of Medical Sciences, Poland \\ (iD) https://orcid.org/0000-0002-3284-3665
}

DOI: https://doi.org/10.20883/medical.e504

Keywords: arterial stiffness, exercise, post-exercise recovery, hypertension

Published: 2021-03-30

How to Cite: Miętkiewska-Szwacka K, Magdalena Kujawska-Łuczak, Tomasz Piorunek, Szczepan Cofta, Karolina Hoffmann, Katarzyna Grabańska-Martyńska, Magdalena Roszak, Ewa Wysocka, Maciej Cymerys. The effects of submaximal exercise on a treadmill on the recovery of the stiffness index and reflection index in men with untreated hypertension. JMS [Internet]. 2021 Mar 30;90(1):e504 doi:10.20883/medical.e504

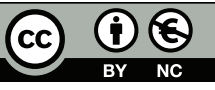

(c) 2021 by the author(s). This is an open access article distributed under the terms and conditions of the Creative Commons Attribution (CC BY-NC) licencse. Published by Poznan University of Medical Sciences

\section{ABSTRACT}

Aim. Increased arterial stiffness is a risk factor for cardiovascular disease (CVD). Adult men with untreated hypertension are at risk of future CVD. The study aimed to compare the effects of a submaximal exercise on the recovery of the two descriptors of arterial pressure waveform, i.e. stiffness index (SI) and reflection index $(\mathrm{RI})$, between men with untreated hypertension $(\mathrm{HA})$ and healthy peers.

Material and Methods. The study included 70 Caucasian men with untreated primary HA and 30 normotensive men. Blood pressure, SI and RI were determined by photoplethysmography before and 6 minutes after a submaximal (up to $85 \%$ of age-predicted maximal heart rate) exercise on a treadmill. 
Results. Baseline SI was higher in HA than control men $(6.06$ [0.66] vs. $6.61[0.84] \mathrm{m} / \mathrm{s} ; \mathrm{p}=0.0019)$ and remained significantly increased during post-exercise recovery only in HA men (7.59 [1.6] vs. 6.18 [0.85] $\mathrm{m} / \mathrm{s} ; \mathrm{p}<0.0001)$. Pre-exercise RI did not differ between HA and healthy men (50.74 [14.17] vs 48.9 [14.86]\%). Six minutes after the exercise, RI higher in HA patients than in healthy men (45.26[15.33] vs 36.2 [13.18]\%; $\mathrm{p}=0.0058$ ).

Conclusions. Arterial stiffness is higher in men with HA both at rest and 6 minutes after exercise. Compared with healthy men, those with HA have more increased arterial tone and impaired vasodilation but only during the recovery. It suggests that untreated HA patients have abnormal mechanical properties of arterial pressure waveforms during the post-exercise recovery.

\section{Introduction}

A submaximal exercise treadmill test (ETT) is an effective and readily available method to assess the blood pressure response (BP) during exercise. It is also an important diagnostic tool in cardiovascular (CV) system evaluation [1,2]. Typically, exercise induces an increase in systolic blood pressure (SBP) and no change or a mild reduction in diastolic blood pressure (DBP), with a decline of both during post-exercise recovery in healthy people [3]. However, hypertension is accompanied by a higher increase in SBP and no drop or even a raise of DBP. Nevertheless, both SBP and DBP decrease during recovery in patients with $H A$, consequently, regular exercise is recommended as a treatment for HA treatment [4-6].

Arterial stiffness is a recognised risk factor for $\mathrm{CV}$ disease (CVD) and is influenced by age, hypertension, male sex, diabetes, obesity and smoking etc. [7-10]. Increased arterial stiffness is a marker of subclinical organ damage in patients with HA [11]. As such, the European Network for Non-invasive Investigation of Large Arteries advises that arterial stiffness is evaluated in large and medium-sized arteries to estimate CVD risk, especially in hypertensive patients without evidence of organ damage [12]. Furthermore, epidemiological studies have revealed the predictive value of arterial stiffness for fatal and non-fatal CV events in patients with hypertension [13], renal failure [14], type 2 diabetes [15] and in healthy people [16].

Arterial stiffness and other mechanical properties of arterial pressure waveforms, e.g. arterial distensibility, tone or vasodilation, are mainly assessed at rest, either in sitting or lying subjects. Physical exercise, for example, induces several hemodynamic and metabolic responses during ETT. Post-exercise recovery is a resting phase after ceasing physical effort and is accompanied by several physiological adaptations like reduction in myocardial oxygen demand, SBP or heart rate, removal of excessive heat or lactate produced by working muscles $[17,18]$. These post-exercise changes are believed to be beneficial, particularly in people with CV risk factors and disease. However, arterial mechanical properties have not been extensively studied in hypertensive patients in post-exercise recovery. For this reason, we aimed to compare the effects of submaximal ETT on the post-exercise recovery of two descriptors of the arterial waveforms, i.e., the Stiffness Index (SI) and the Reflection Index (RI) in hypertensive and healthy men. SI indirectly quantifies how stiff the arterial wall is, i.e. it increases with more rigid and thick arteries that become less distensible, whereas $\mathrm{RI}$ reflects the net peripheral arterial wall tone and effects of vasodilation of smaller arteries and arterioles [15].

\section{Material and Methods}

\section{Study design and test subjects}

The study population comprised 70 Caucasian men with untreated primary arterial hypertension and 30 healthy men aged 20 to 40 years. The preliminary diagnosis of HA was based on BP measurements according to the current European Society of Cardiology and European Society of Hypertension (ESH) Guidelines [11] and confirmed or excluded in all subjects by ambulatory blood pressure monitoring by an oscillometric method (TM-2430, A\&D Medical, Japan) using the same recommendations.

The exclusion criteria were: (1) a history of symptoms suggesting secondary hypertension; (2) coronary heart disease, diabetes, cere- 
brovascular disease, or thyroid disease, current or past renal disease; (3) medications that may significantly influence the analysed parameters, including aspirin, steroids, statins, non-steroidal anti-inflammatory drugs, or psychotic agents; (4) body mass index (BMI) equal to or greater than $40 \mathrm{~kg} / \mathrm{m} 2$; (5) left ventricular hypertrophy, cardiac arrhythmias, or atrioventricular conduction disturbances in the resting 12-lead electrocardiography (ECG); (6) any abnormalities in the serum concentration of sodium, potassium, chloride, uric acid, or creatinine, and C-reactive protein (CRP); (7) fasting plasma glucose above $7.0 \mathrm{mmol} / \mathrm{l}$ or glycated haemoglobin (HbA1c) above $6.5 \%$. All blood samples were analysed in the Central Laboratory of the Clinical Hospital of Transfiguration (Poznan, Poland) using standard laboratory methods.

The study protocol was reviewed and approved by an independent ethics committee (Bioethics Commission at Poznan University of Medical Sciences, approval no. 258/08, issued 6 March 2008). Informed written consent was obtained before the first study procedure.

\section{Measurement of baseline characteristics}

All individuals underwent anthropometric measurements (weight, height) and BMI was calculated using the formula: $\mathrm{BMI}=$ weight $[\mathrm{kg}] /$ (height $[\mathrm{m}])^{2}$. Biochemical parameters were assessed in fasting serum. All patients ate a standard breakfast and ECG exercise testing was performed two hours later (detailed below). None of the participants smoked before the test. BP measurements were performed following the ESH guidelines on HA [11]. The resting pulse pressure (PP) was calculated as the difference between the systolic and diastolic BP: PP = SBP - DBP.

\section{Exercise test}

The CardioTEST Alfa System B612 was used for the ECG exercise test with CardioTEST software and a Treadmill B612 model C with the 12 lead ECG module (Aspel, Poland). According to the Bruce protocol, the test was conducted and stopped when subjects achieved submaximal exercise $(85 \%$ of their maximum estimated heart rate according to the formula 220 - age).

Exercise tolerance was estimated with the metabolic equivalents (METs) computed automatically by the applied software for the ETT. One
MET is defined as the amount of oxygen consumed while sitting at rest and is equal to $3.5 \mathrm{ml}$ 02 per $\mathrm{kg}$ body weight $\mathrm{x} \min [19,20]$. The following parameters were considered during the interpretation of this test: (1) SBP, DBP and PP, and HR at rest, at the peak of exercise and six minutes after the exercise during recovery.

\section{Evaluation of mechanical properties} of arterial pressure waveforms

Arterial stiffness was measured by digital volume pulse (DVP) photoplethysmography using a Pulse Trace PCA2 (Micro Medical Ltd, Rochester, UK). DVP was recorded in the subject's right index finger. The measurements were performed in triplicate (recorded for $30 \mathrm{~s}$ ), an average was calculated and used for the analysis. All the patient measurements were performed on the same day by the same operator [21]. An explanation of how SI and RI were derived and computed from the DVP analysis is shown in Figure 1 [21]. $S I$ reflects the stiffness and arterial distensibility [22], and the SI from DVP correlates highly with aortic PWV measured by other methods [23]. RI reflects the vascular tone of small vessels and estimates peripheral vasodilation [24]. Both resting and post-exercise measures $\mathrm{SI}$ and $\mathrm{RI}$ were performed three times in the supine position; the respective means were used for calculations. As DVP should be applied during the resting condition, neither SI nor RI was measured at the exercise peak like HR or BP parameters.

\section{Statistical analysis}

The Shapiro-Wilk test was used to evaluate the normality of the distribution of continuous data, which were presented as the mean and standard deviation (SD). Paired t-tests were conducted for comparisons between rest, submaximal exercise and post-exercise recovery for healthy men and HA patients. Independent t-tests were conducted to determine differences between the two groups for each phase, i.e. either rest or submaximal exercise or post-exercise recovery. Statistical analyses were performed using the MedCalc ${ }^{\circledR}$ Statistical Software version 19.5.3 (MedCalc Software Ltd, Ostend, Belgium; https://www. medcalc.org; 2020) and two-sided tests, with the significance set at $\mathrm{p}<0.05$. 


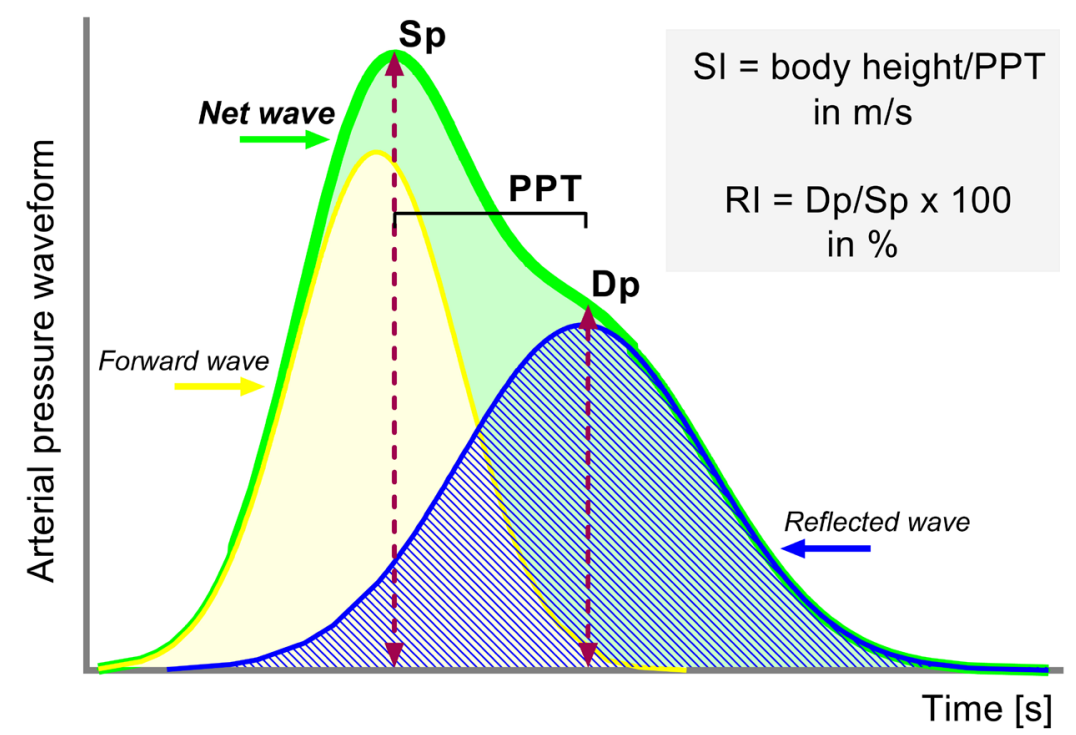

Figure 1. Schematic representation of arterial pressure waveform, its systolic peak (Sp), diastolic peak (Dp), the distance between the two peaks (peak-to-peak time - PPT). The Stiffness Index (SI) is obtained from subject height divided by the time between $\mathrm{Sp}$ and Dp, whereas the Reflection Index (RI) is determined as the ratio of the height of the Dp to the Dp [33]

\section{Statistical analysis}

The Shapiro-Wilk test was used to evaluate the normality of the distribution of continuous data. Their summary is presented as the mean and standard deviation (SD). The comparisons between rest, submaximal exercise and postexercise recovery were made with the paired $\mathrm{t}$-test for healthy men and HA patients. The Comparison between these two groups for the same phase, i.e. either rest or submaximal exercise or post-exercise recovery, was made in the $t$-test for independent (unpaired) data. Statistical analyses were performed using the Statistica 10 software (StatSoft Polska, Sp. z o.o., Krakow, Poland). The results were carried out using two-sided tests, and significance was set at $p<0.05$.

\section{Results}

\section{Baseline characteristics}

Baseline clinical characteristics of all subjects are shown in Table 1. Men with HA were significantly older (app 3.3. years) but the mean age difference of 3 years does not seem to be of clinical relevance in our relatively young group. HA patients had a higher BMI of about $4.3 \mathrm{~kg} / \mathrm{m}^{2}$ and body weight of over $14 \mathrm{~kg}$, and their achieved 2.5 less METs during submaximal exercise.

Table 1. Baseline clinical characteristics of healthy men and hypertensive subjects. Data are presented as mean and standard deviation (SD). Comparisons are made with the unpaired t-test between healthy and HA men BMI, body mass index: MET. metabolic equivalent

\begin{tabular}{lccccc} 
& \multicolumn{2}{c}{$\begin{array}{c}\text { Healthy men } \\
\mathbf{N}=\mathbf{3 0}\end{array}$} & \multicolumn{2}{c}{$\begin{array}{c}\text { Hypertensive men } \\
\mathbf{N}=\mathbf{7 0}\end{array}$} \\
\cline { 2 - 6 } & Mean & SD & Mean & SD & P-value $^{\text {a }}$ \\
\hline Age, years & 24.37 & 2.43 & 28.13 & 5.27 & 0.0003 \\
\hline BMI, $\mathrm{kg} / \mathrm{m}^{2}$ & 23.21 & 2.16 & 27.56 & 3.77 & $<0.0001$ \\
\hline MET & 13.12 & 2.56 & 10.62 & 2.37 & $<0.0001$ \\
\hline Waist, $\mathrm{cm}$ & 82.13 & 6.63 & 93.71 & 11.40 & $<0.0001$ \\
\hline Weight, $\mathrm{kg}$ & 74.47 & 7.90 & 88.87 & 13.22 & $<0.0001$ \\
\hline Height, $\mathrm{m}$ & 1.79 & 0.07 & 1.79 & 0.06 & 0.8085 \\
\hline
\end{tabular}

Abbreviations: BMI, body mass index; MET, metabolic equivalent 


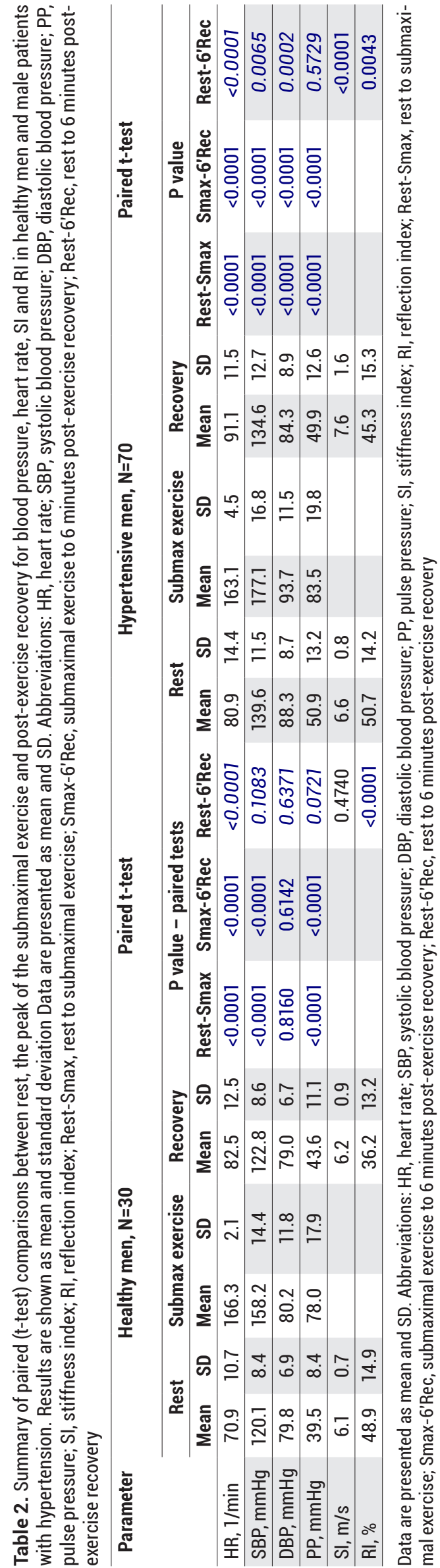

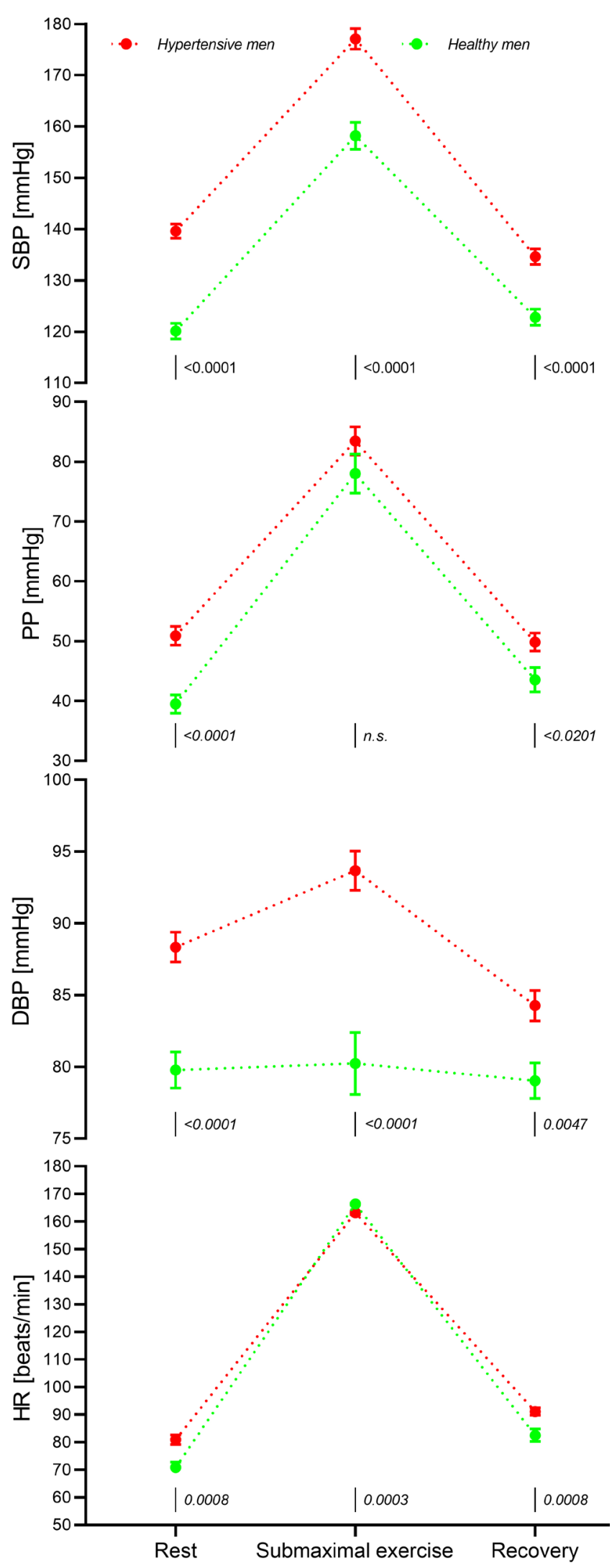

Figure 2. Comparison (unpaired t-test) of blood pressure and heart rate at rest, the peak of submaximal exercise and post-exercise recovery between men with and without hypertension. For details and abbreviations, please refer to the main text. Results are shown as the mean and standard error of the mean 
Comparison of resting hemodynamic and arterial pressure waveform descriptors between healthy men and patients with hypertension Figure 2 shows that the resting SBP, DBP, PP and $\mathrm{HR}$ were higher in HA patients than in healthy men.

The $\mathrm{BP}$ and HR during resting conditions, submaximal exercise and post-exercise recovery in healthy and hypertensive men are shown in Table 2. HR, PP and SBP significantly increased during submaximal exercise, then declined during recovery in both healthy men and those with hypertension. In HA men, DBP was higher at the peak of the submaximal exercise than at rest and declined during the recovery but was still higher than at rest. In contrast, neither submaximal exercise nor post-exercise recovery affected DBP in healthy men.

Compared with rest, SI was higher during postexercise recovery only in HA patients, whereas RI declined both in healthy and hypertensive men (Table 2). HR, SBP, PP significantly increased in submaximal exercise and post-exercise recovery both in HA and healthy subjects. In contrast, DBP significantly declines in post-exercise recovery only in HA compared to healthy men. SI did not change in healthy subjects during post-exercise recovery, whereas SI was significantly higher in HA patients. RI significantly dropped in both groups during post-exercise recovery.

Resting and post-exercise SBP, DBP, PP and $\mathrm{HR}$ were higher in HA patients than in healthy men (Table 2 and Figure 2). At the peak of submaximal exercise, SBP and DBP were higher while HR was lower in HA men. Also, SI but not RI was significantly higher in men with HA than in healthy subjects (Table 2 and Figure 3).

\section{Effects of the submaximal exercise and post-} exercise recovery on hemodynamic and arterial pressure waveform descriptors in healthy men and patients with hypertension $H R$, PP and SBP significantly increased during submaximal exercise, then declined during the
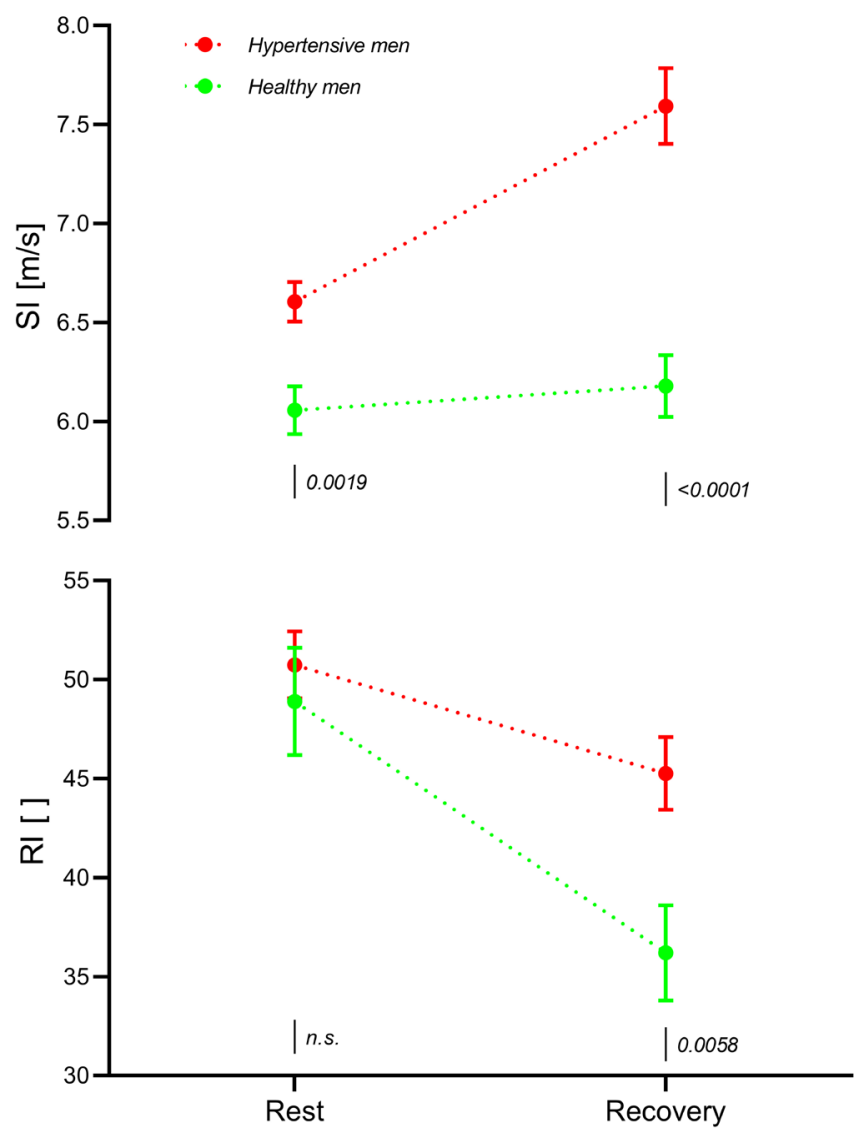

Figure 3. Comparisons (unpaired t-test) of the stiffness index and reflection index derived from the Digital Volume Pressure analysis of arterial pressure waveforms between healthy and HA men 
post-exercise recovery both in healthy men and those with hypertension (Table 2, Figures 2-3). In HA men, DBP was higher at the peak of the submaximal exercise than at rest and declined during the recovery but was still higher than at rest. In contrast, neither submaximal exercise nor post-exercise recovery affected DBP in healthy men. Compared with rest, SI was higher during post-exercise recovery only in HA patients, whereas RI declined both in healthy and hypertensive men.

Comparison of hemodynamic and arterial pressure waveform descriptors between healthy men and patients with hypertension at the peak of submaximal exercise and 6 minutes of the post-exercise recovery

Figure 2 shows that SBP and DBP were higher at the peak of submaximal exercise and during recovery in HA men than healthy individuals. PP was significantly higher in HA patients only during the recovery. In contrast, HR was lower in HA men at the peak of the exercise, and then it was higher during the recovery in HA patients. Figure 3 reveals that compared to healthy men, $\mathrm{SI}$ was higher and RI was lower in HA patients.

\section{Discussion}

In addition to significant BP and HR changes, we found that the arterial wall mechanical properties are modified by submaximal exercise both in $\mathrm{HA}$ and healthy men. After submaximal exercise, SI increased in HA men, with no change in healthy individuals. Although no difference in the resting $\mathrm{RI}$ was found between healthy subjects and HA patients, RI significantly decreased during postexercise recovery in both groups. It is noteworthy that $\mathrm{RI}$ decline during post-exercise recovery was deeper in healthy than HA patients.

The results of the Baltimore Longitudinal Study of Aging [25] and the study by Kaess et al. demonstrated that higher arterial stiffness in normotensive individuals might predict hypertension development [26]. In our investigation, HA patients had higher baseline SI compared to healthy individuals of the same age, in line with the results reported by Millasseau et al. [10]. SI increased in HA patients but not in the normotensive group.
Regular physical activity is beneficial for the CV system, including BP and HR [4]. In older adults with multiple $\mathrm{CV}$ risk factors, short-term improvements in the arterial stiffness induced by a regular aerobic exercise were attenuated over the long term of no activity [27]. Nevertheless, in pre- and hypertensive subjects, arterial stiffness was not modified by aerobic training unless the exercise was associated with a substantial reduction in SBP and/or prolonged duration of the intervention [28].

To date, only a few studies have examined the impact of a single bout of physical activity on arterial stiffness. Sharman et al. studied the effects of a stable, low-intensity exercise at the level of $60 \%$ of the predicted maximal heart rate in healthy people of different ages as with and without hypercholesterolemia [29]. All participants exercised on an ergometric stationary bicycle for 10 minutes with the ergometer resistance adjusted to maintain a steady-state heart rate. The aortic pulse wave timing, the augmentation index and $\mathrm{PP}$ amplification at 2-minute intervals were measured during exercise and 10 minutes after completion. The exercise caused no significant differences in the aortic pulse wave timing, however, the augmentation index decreased and the PP amplification declined during the exercise regardless of the presence or absence of hypercholesterolemia or participant age. Hu et al. found that PP, which is related to the arterial stiffness and stroke volume, remained increased 3 minutes after an aerobic exercise on a cycle ergometer in healthy people [30]. Heffernan et al. found no statistical difference in the pulse wave velocity 15 and 30 minutes after exercise in young white and Afro-American healthy men regardless of race [31]. Tabara et al. observed no significant change in the augmentation index of healthy and sedentary elderly subjects who underwent mild-to-moderate aerobic exercise (dancing and hopping) for 30 minutes, followed by a 5-minute cooldown [32].

All the mentioned studies and our results show different effects of exercise on mechanical properties of arterial pressure waveforms during recovery. There are several reasons for this, such as the use of different exercise protocols, for instance, the exercise treadmill in our study, ergometric stationary bicycle in studies by Sharman et al. [29], Hu et al. [30] and Heffernan et al. [31]. Also, the intensity and duration of the exer- 
cise were different, e.g. mild aerobic, submaximal or exhaustion, endurance or resistant with some lasting up to six minutes and others to thirty minutes. Moreover, the mechanical properties of arterial pressure waveforms were made with various methods (applanation tonometry, photoplethysmography) and parameters (pulse wave velocity, augmentation index, PP, PP augmentation, aortic pulse wave timing $\mathrm{SI}$ and RI). Additionally, the measurements were taken at different postexercise recovery phases between 10 to $30 \mathrm{~min}$ utes or after the heart rate returned to the preexercise baseline level. Finally, various groups were investigated, healthy young or older people, hypertension, hypercholesterolemia or other risk factors, both genders or men only. Consequently, it is not surprising that there is no agreement on the effects of exercise on the arterial pressure waveform mechanical properties. Therefore, our findings cannot be easily compared with other studies on post-exercise recovery.

We show that baseline SI, directly associated with arterial stiffness, was higher in the HA than in healthy men, and it was still increased during the post-exercise recovery. In contrast, pre- and post-exercise SI remained unchanged in healthy men. Moreover, RI, related to the vascular tone of small arteries/arterioles and arterial vasodilation, remained reduced during the post-exercise recovery both in healthy people and HA men. Nevertheless, the degree of $\mathrm{RI}$ reduction during recovery appears to be attenuated in men with untreated primary HA. During the recovery, the decline of RI suggests that the tone of small arteries is reduced, possibly due to improved arterial vasodilation.

Exercise is a physiological challenge that triggers a series of hemodynamic changes. We demonstrate that some exercise effects on BP profile, $\mathrm{HR}$ and mechanical properties of arterial walls are still visible 6 minutes after the exercise is stopped. We compared the post-exercise effects only in healthy men and subjects with untreated HA. The employed model can be easily reproduced and applied to different clinical scenarios or to investigate the effects of various pharmacological agents, for instance, used in the treatment of $\mathrm{HA}$, as well as research the long-term effects of regular endurance and resistant training on SI and RI in HA patients. According to the most recent ESC guidelines on sports cardiology and physical exercise, regular endurance training should last a minimum of 30 minutes a day at least five times a week and resistance training should be taken for a minimum of 15 minutes and be repeated at least three times a week in HA patients [4]. However, the consequences of such recommendations on the mechanical properties of arterial walls are unknown.

Some limitations of the present study must be acknowledged. First, the study was performed on men, thus the results cannot be extrapolated to women. Another limitation is that all studied participants were relatively young to make general conclusions for a wide age range. All patients with HA were untreated to avoid potential interactions of pharmacological agents on our results. However, as already mentioned, our model can be easily transferred to pharmacological studies in HA patients. Finally, we only applied indirect measures of arterial mechanical properties. Nonetheless, the photoplethysmographic DVP has been extensively used both in research and clinical studies in different groups of patients, including those with $\mathrm{HA}$ [33].

\section{Conclusions}

This study demonstrated that young and middleaged hypertensive men exhibit higher baseline and post-exercise arterial stiffness parameters than similar age normotensive individuals. Furthermore, vascular tone declines but vasodilation improves during the post-exercise recovery, although the magnitude of these changes is attenuated in patients with HA. This model can be easily applied to study the effect of pharmacological antihypertensive therapy on the mechanical properties of arterial walls.

\section{Acknowledgements}

\section{Conflict of interest statement}

The authors declare no conflict of interest.

\section{Funding sources}

The study was supported by Poznan University of Medical Science, Poland under grant number 500-0111191740.

\section{References}

1. Vehrs PR, George JD, Fellingham GW, Plowman SA, Dustman-Allen K. Submaximal Tread- 
mill Exercise Test to Predict VO2max in Fit Adults. Measurement in Physical Education and Exercise Science. 2007 Apr 12;11(2):61-72. https://doi. org/10.1080/10913670701294047

2. Wielemborek-Musial K, Szmigielska K, Leszczynska $\mathrm{J}$, Jegier A. Blood Pressure Response to Submaximal Exercise Test in Adults. BioMed Research International. 2016;2016:1-8. https://doi.org/10.1155/2016/5607507

3. Sietsema KE, Sue DY, Stringer WW, Ward S. Wasserman \& Whipp's Principles of Exercise Testing and Interpretation. 6th ed. Wolters Kluwer Health; 2020.

4. Pelliccia A, Sharma $S$, Gati $S$, Bäck $M$, Börjesson $\mathrm{M}$, Caselli S, Collet J, Corrado D, Drezner JA, Halle $M$, Hansen D, Heidbuchel H, Myers J, Niebauer J, Papadakis M, Piepoli MF, Prescott E, Roos-Hesselink JW, Graham Stuart A, Taylor RS, Thompson PD, Tiberi M, Vanhees L, Wilhelm M, Guazzi M, La Gerche A, Aboyans V, Adami PE, Backs J, Baggish A, Basso C, Biffi A, Bucciarelli-Ducci C, Camm AJ, Claessen G, Delgado V, Elliott PM, Galderisi M, Gale CP, Gray $B$, Haugaa KH, lung B, Katus HA, Keren A, Leclercq C, Lewis BS, Mont L, Mueller C, Petersen SE, Petronio AS, Roffi M, Savonen K, Serratosa L, Shlyakhto E, Simpson IA, Sitges M, Solberg EE, Sousa-Uva M, Van Craenenbroeck E, Van De Heyning C, Wijns W, Gati S, Bäck M, Börjesson M, Caselli S, Collet J, Corrado D, Drezner JA, Halle M, Hansen D, Heidbuchel H, Myers J, Niebauer J, Papadakis M, Piepoli MF, Prescott E, Roos-Hesselink JW, Stuart AG, Taylor RS, Thompson PD, Tiberi M, Vanhees L, Wilhelm M. 2020 ESC Guidelines on sports cardiology and exercise in patients with cardiovascular disease. European Heart Journal. 2020 Aug 29;42(1):17-96. https://doi.org/10.1093/eurheartj/ehaa605

5. Bull FC, Al-Ansari SS, Biddle S, Borodulin K, Buman MP, Cardon G, Carty C, Chaput J, Chastin S, Chou R, Dempsey PC, DiPietro L, Ekelund U, Firth J, Friedenreich CM, Garcia L, Gichu M, Jago R, Katzmarzyk PT, Lambert E, Leitzmann M, Milton K, Ortega FB, Ranasinghe $\mathrm{C}$, Stamatakis $\mathrm{E}$, Tiedemann A, Troiano RP, van der Ploeg HP, Wari V, Willumsen JF. World Health Organization 2020 guidelines on physical activity and sedentary behaviour. British Journal of Sports Medicine. 2020 Nov 25;54(24):1451-62. https://doi. org/10.1136/bjsports-2020-102955

6. Physical Activity and Public Health. Circulation. 2007 Aug 28;116(9):1081-93. https://doi.org/10.1161/ circulationaha.107.185649

7. Lakatta EG, Levy D. Arterial and Cardiac Aging: Major Shareholders in Cardiovascular Disease Enterprises. Circulation. 2003 Jan 07;107(1):139-46. https://doi. org/10.1161/01.cir.0000048892.83521.58

8. O'Rourke MF, Nichols WW. Aortic Diameter, Aortic Stiffness, and Wave Reflection Increase With Age and Isolated Systolic Hypertension. Hypertension. 2005 Apr;45(4):652-8. https://doi.org/10.1161/01. hyp.0000153793.84859.b8

9. NICHOLS W. Clinical measurement of arterial stiffness obtained from noninvasive pressure waveforms. American Journal of Hypertension. 2005 Jan;18:3-10. https://doi.org/10.1016/j.amjhyper.2004.10.009
10. MILLASSEAU S, KELLY R, RITTER J, CHOWIENCZYK P. Determination of age-related increases in large artery stiffness by digital pulse contour analysis. Clinical Science. 2002 Aug 30;103(4):371-7. https://doi. org/10.1042/cs1030371

11. Williams B, Mancia G, Spiering W, Agabiti Rosei E, Azizi M, Burnier M, Clement DL, Coca A, de Simone G, Dominiczak A, Kahan T, Mahfoud F, Redon J, Ruilope L, Zanchetti A, Kerins M, Kjeldsen SE, Kreutz R, Laurent S, Lip GYH, McManus R, Narkiewicz K, Ruschitzka F, Schmieder RE, Shlyakhto E, Tsioufis C, Aboyans V, Desormais I, De Backer G, Heagerty AM, Agewall S, Bochud M, Borghi C, Boutouyrie P, Brguljan J, Bueno H, Caiani EG, Carlberg B, Chapman N, Cífková $\mathrm{R}$, Cleland JGF, Collet J, Coman IM, de Leeuw PW, Delgado V, Dendale P, Diener H, Dorobantu M, Fagard R, Farsang C, Ferrini M, Graham IM, Grassi G, Haller H, Hobbs FDR, Jelakovic B, Jennings $C$, Katus HA, Kroon $A A$, Leclercq C, Lovic D, Lurbe E, Manolis AJ, McDonagh TA, Messerli F, Muiesan ML, Nixdorff U, Olsen MH, Parati G, Perk J, Piepoli MF, Polonia J, Ponikowski P, Richter DJ, Rimoldi SF, Roffi M, Sattar N, Seferovic PM, Simpson IA, Sousa-Uva M, Stanton AV, van de Borne P, Vardas $\mathrm{P}$, Volpe $\mathrm{M}$, Wassmann S, Windecker S, Zamorano JL, Windecker $S$, Aboyans V, Agewall S, Barbato E, Bueno H, Coca A, Collet J, Coman IM, Dean V, Delgado $V$, Fitzsimons $D$, Gaemperli $O$, Hindricks $G$, lung $B$, Jüni $P$, Katus HA, Knuuti J, Lancellotti $P$, Leclercq C, McDonagh TA, Piepoli MF, Ponikowski P, Richter DJ, Roffi M, Shlyakhto E, Simpson IA, Sousa-Uva M, Zamorano JL, Tsioufis C, Lurbe E, Kreutz R, Bochud $M$, Rosei EA, Jelakovic B, Azizi $M$, Januszewics $A$, Kahan T, Polonia J, van de Borne P, Williams B, Borghi C, Mancia G, Parati G, Clement DL, Coca A, Manolis A, Lovic D, Benkhedda S, Zelveian P, Siostrzonek $P$, Najafov R, Pavlova O, De Pauw M, Dizdarevic-Hudic L, Raev D, Karpettas N, Linhart A, Olsen MH, Shaker AF, Viigimaa M, Metsärinne $K$, Vavlukis $M$, Halimi J, Pagava $Z$, Schunkert $H$, Thomopoulos $C$, Páll $D$, Andersen K, Shechter M, Mercuro G, Bajraktari G, Romanova T, Trušinskis K, Saade GA, Sakalyte G, Noppe S, DeMarco DC, Caraus A, Wittekoek J, Aksnes TA, Jankowski P, Polonia J, Vinereanu D, Baranova El, Foscoli M, Dikic AD, Filipova S, Fras Z, Bertomeu-Martínez V, Carlberg B, Burkard T, Sdiri W, Aydogdu S, Sirenko Y, Brady A, Weber T, Lazareva I, Backer TD, Sokolovic S, Jelakovic B, Widimsky J, Viigimaa M, Pörsti I, Denolle T, Krämer BK, Stergiou GS, Parati G, Trušinskis K, Miglinas $M$, Gerdts E, Tykarski A, de Carvalho Rodrigues $M$, Dorobantu M, Chazova I, Lovic D, Filipova S, Brguljan $J$, Segura J, Gottsäter A, Pechère-Bertschi A, Erdine S, Sirenko Y, Brady A. 2018 ESC/ESH Guidelines for the management of arterial hypertension. European Heart Journal. 2018 Aug 25;39(33):3021-104. https:// doi.org/10.1093/eurheartj/ehy339

12. Laurent S, Cockcroft J, Van Bortel L, Boutouyrie P, Giannattasio C, Hayoz D, Pannier B, Vlachopoulos C, Wilkinson I, Struijker-Boudier H. Expert consensus document on arterial stiffness: methodological issues and clinical applications. European Heart Journal. 2006 Sep 25;27(21):2588-605. https://doi. org/10.1093/eurheartj/ehl254 
13. Laurent S, Boutouyrie P, Asmar R, Gautier I, Laloux B, Guize L, Ducimetiere P, Benetos A. Aortic Stiffness Is an Independent Predictor of All-Cause and Cardiovascular Mortality in Hypertensive Patients. Hypertension. 2001 May;37(5):1236-41. https://doi. org/10.1161/01.hyp.37.5.1236

14. De Jong MA, Van Roon AM, Bakker JT, Bijen HT, Mulder DJ, Brouwers FP, Van Gilst WH, Voors AA, Gansevoort RT, Bakker SJ, De Borst MH. Digital arterial pressure pulse wave analysis and cardiovascular events in the general population: the Prevention of Renal and Vascular End-stage Disease study. Journal of Hypertension. 2020 Jun;38(6):1064-71. https://doi. org/10.1097/hjh.0000000000002390

15. Cruickshank K, Riste L, Anderson SG, Wright JS, Dunn G, Gosling RG. Aortic Pulse-Wave Velocity and Its Relationship to Mortality in Diabetes and Glucose Intolerance. Circulation. 2002 Oct 15;106(16):208590. https://doi.org/10.1161/01.cir.0000033824.02722. f7

16. Mattace-Raso FU, van der Cammen TJ, Hofman A, van Popele NM, Bos ML, Schalekamp MA, Asmar R, Reneman RS, Hoeks AP, Breteler MM, Witteman JC. Arterial Stiffness and Risk of Coronary Heart Disease and Stroke. Circulation. 2006 Feb 7;113(5):657-63. https:// doi.org/10.1161/circulationaha.105.555235

17. Joyner MJ, Casey DP. Regulation of Increased Blood Flow (Hyperemia) to Muscles During Exercise: A Hierarchy of Competing Physiological Needs. Physiological Reviews. 2015 Apr;95(2):549-601. https://doi. org/10.1152/physrev.00035.2013

18. Romero SA, Minson CT, Halliwill JR. The cardiovascular system after exercise. Journal of Applied Physiology. 2017 Apr 1;122(4):925-32. https://doi.org/10.1152/ japplphysiol.00802.2016

19. Jetté M, Sidney K, Blümchen G. Metabolic equivalents (METS) in exercise testing, exercise prescription, and evaluation of functional capacity. Clinical Cardiology. 1990 Aug;13(8):555-65. https://doi.org/10.1002/ clc. 4960130809

20. Kowalska M, Fehlau M, Cymerys M, Guzik P. A thousand words about running fitness tests. Journal of Medical Science. 2019 Mar 13;88(3):184-91. https:// doi.org/10.20883/jms.344

21. Gunarathne A, Patel JV, Hughes EA, Lip GYH. Measurement of Stiffness Index by Digital Volume Pulse Analysis Technique: Clinical Utility in Cardiovascular Disease Risk Stratification. American Journal of Hypertension. 2008 Aug 1;21(8):866-72. https://doi. org/10.1038/ajh.2008.207

22. Millasseau SC, Ritter JM, Takazawa K, Chowienczyk PJ. Contour analysis of the photoplethysmographic pulse measured at the finger. Journal of Hypertension. 2006 Aug;24(8):1449-56. https://doi.org/10.1097/01. hjh.0000239277.05068.87

23. Clarenbach CF, Stoewhas A, van Gestel AJ, Latshang TD, Lo Cascio CM, Bloch KE, Kohler M. Comparison of photoplethysmographic and arterial tonometry-derived indices of arterial stiffness. Hyperten- sion Research. 2011 Oct 13;35(2):228-33. https://doi. org/10.1038/hr.2011.168

24. Wykretowicz A, Trojnarska O, Guzik P, Katarzyska A. Arterial Stiffness in Adult Patients with Cyanotic Congenital Heart Disease. Congenital Heart Disease. 2007 Mar;2(2):134-8. https://doi.org/10.1111/j.17470803.2007.00087.x

25. Najjar SS, Scuteri A, Shetty V, Wright JG, Muller DC, Fleg JL, Spurgeon HP, Ferrucci L, Lakatta EG. Pulse Wave Velocity Is an Independent Predictor of the Longitudinal Increase in Systolic Blood Pressure and of Incident Hypertension in the Baltimore Longitudinal Study of Aging. Journal of the American College of Cardiology. 2008 Apr;51(14):1377-83. https://doi. org/10.1016/j.jacc.2007.10.065

26. Kaess BM, Rong J, Larson MG, Hamburg NM, Vita JA, Levy D, Benjamin EJ, Vasan RS, Mitchell GF. Aortic Stiffness, Blood Pressure Progression, and Incident Hypertension. JAMA. 2012 Sep 5;308(9):875. https:// doi.org/10.1001/2012.jama.10503

27. Madden KM, Lockhart C, Cuff D, Potter TF, Meneilly GS. Aerobic training-induced improvements in arterial stiffness are not sustained in older adults with multiple cardiovascular risk factors. Journal of Human Hypertension. 2012 Sep 6;27(5):335-9. https://doi. org/10.1038/jhh.2012.38

28. Montero D, Roche E, Martinez-Rodriguez A. The impact of aerobic exercise training on arterial stiffness in pre- and hypertensive subjects: A systematic review and meta-analysis. International Journal of Cardiology. 2014 May;173(3):361-8. https://doi. org/10.1016/j.ijcard.2014.03.072

29. Sharman JE, McEniery CM, Dhakam ZR, Coombes JS, Wilkinson IB, Cockcroft JR. Pulse pressure amplification during exercise is significantly reduced with age and hypercholesterolemia. Journal of Hypertension. 2007 Jun;25(6):1249-54. https://doi.org/10.1097/ hjh.0b013e3280be5911

30. Hu M, Yan H, Ranadive SM, Agiovlasitis S, Fahs CA, Atiq $M$, Atique N, Fernhall B. Arterial stiffness response to exercise in persons with and without Down syndrome. Research in Developmental Disabilities. 2013 Oct;34(10):3139-47. https://doi.org/10.1016/j. ridd.2013.06.041

31. Heffernan K, Jae S, Fernhall B. Racial Differences in Arterial Stiffness After Exercise in Young Men. American Journal of Hypertension. 2007 Aug;20(8):840-5. https://doi.org/10.1016/j.amjhyper.2007.03.015

32. Tabara $Y$, Yuasa T, Oshiumi A, Kobayashi T, Miyawaki Y, Miki T, Kohara K. Effect of Acute and LongTerm Aerobic Exercise on Arterial Stiffness in the Elderly. Hypertension Research. 2007;30(10):895-902. https://doi.org/10.1291/hypres.30.895

33. Wykretowicz A, Adamska K, Guzik P, Zwanzig M, Dziarmaga M, Krauze T. Comparison of beta2-adrenergic and hyperemia-induced arterial vasodilation assessed by digital pulse contour analysis. Journal of Medical Science. 2019 Mar 9;88(1):7-11. https://doi. org/10.20883/jms.330 